\title{
Complex Psycho-Lingua-Economic Expertise in Considering Cases of Business Reputation Protection
}

\author{
O.V. Dubrovin \\ South Ural State University \\ Department of Constitutional and Administrative Law \\ Chelyabinsk, Russia \\ pominoff@mail.ru
}

L.M. Safiullina

Sibai Institute of Bashkir State University

Pedagogical Faculty,

Department of foreign languages

Sibai, Republic of Bashkortostan, Russia, saflu@mail.ru

\author{
A.V. Pominov \\ Sibai Institute of Bashkir State University \\ Pedagogical Faculty, \\ Department of Pedagogy and Psychology \\ Sibai, Republic of Bashkortostan, Russia, \\ pominoff@mail.ru
}

\section{G.N. Mukhamedyanova}

Sibai Institute of Bashkir State University

Pedagogical Faculty,

Department of foreign languages

Sibai, Republic of Bashkortostan, Russia, gulysib@mail.ru

\author{
G.Kh. Samirkhanova \\ Sibai Institute of Bashkir State University \\ Pedagogical Faculty, \\ Department of Bashkir and Russian Philology \\ Sibai, Republic of Bashkortostan, Russia, \\ gulysib@mail.ru
}

\begin{abstract}
The present article is devoted to the investigation of the legal basis of business reputation protection and the ways of proving the utterance character when considering this category of cases. The article also highlights variants of issues on complex psycho-lingua-economic expertise, necessary for justifying the facts which are significant in considering cases of business reputation protection.
\end{abstract}

Keywords-expert activity, judicial expertise, protection of business reputation, complex judicial expertise.

\section{INTRODUCTION}

The term "reputation" is borrowed from the French (Latin) language ("reputation") and means "cogitation", "reflection".

The review of dictionaries allows singling out unity in the definition of the notion "reputation" - an idea of an organization and (or) its production, of a man and (or) his actions established in human minds $[1,2,3,4]$. Thus, speaking in terms of the notion "reputation", one deals with an opinion or representation formed in collective and individual consciousness, positively or negatively assessing the qualities and activity of a person, an organization or products (results). In this connection, one of the purposes of using advertising and PR informational technologies is to make a favorable impression (image).

It should be noted that the meaning of the word "reputation" is indissolubly connected with the image and activity of an individual or legal entity. Explanatory and encyclopedic dictionaries fundamentally point to the bearer of an image - an individual; or, on the contrary, a group of dictionaries defines the organization as a bearer. Herewith, dictionaries differ in subjects but coincide in the unity of the semantic field - image and activity.

Thereby, it is not by chance that the Russian legislation introduced such a definition as "business reputation", and in post-Soviet Russia, the mention of business reputation began with the legislation in the field of banking.

Probably, the origins of this lie in the historical connection between reputation and credit (deferred payment for goods [5, $6]$ ), which more clearly describes the pragmatic component of the notion of reputation.

Article 16, Paragraph 2 of the Law of the USSR from December 11, 1990 No 1829-I "About Banks and Banking Activities" [6] says that bank managers (chairman and chief 
accountant) must possess an impeccable business reputation and have experience in banking.

In addition, according to Article 61 of the Federal Law of December 2, 1990 "About the Central Bank of the Russian Federation (Bank of Russia)" [7], in terms of fulfilling its supervisory functions, it is entitled to request and receive information about the financial position and business reputation of the participants (shareholders). And Article 11 of the Federal Law No. 395-I from December 2, 1990 "About Banks and Banking Activities" says that the Bank of Russia has the right to refuse to give consent for transactions (deals) directed to the purchase of more than 10 percent of the shares of the credit organization and (or) to establish control over the shareholders (participants) of the credit organization in case of an unsatisfactory business reputation of the person making the transaction (transactions) [8].

One should note that the word "reputation" (credit) has three meanings in the sphere of economics (banking):

1. A system of supplying goods and services in exchange for deferred, but not immediate payment.

2. A strong financial reputation that enables a person or company to purchase goods and services not for cash, i.e. on credit.

3. An article of assets in the reporting, i.e. income, or assets [5].

Article 10 of the RSFSR Law from March 22, 1991 No. 948-I "About Competition and Restriction of Monopolistic Activity in Commodity Markets" does not allow unfair competition, including the dissemination of false, inaccurate or distorted information capable of causing losses to another business entity or causing damage to his business reputation [9].

According to Article 6, Paragraph 5 of the RF Law of September 23, 1992 No. 3520-1 "About Trademarks, Service Marks and Appellations of Origin of Goods", in the Russian Federation it is prohibited to register as trademarks the signs representing or containing elements that are protected in one of the states - participants of the specified international treaty as designations identifying wines or spirits as originating from its territory (produced within the borders of the geographical object of that state) and having special qualities, reputation, or other characteristics which are mainly determined by their origin [10].

One of the pillars of the enterprise's activity in the market is the satisfaction of the consumer's needs. In business planning, an entrepreneur faces the task of predicting consumer behavior and creating a "response" model of his company's behavior. The modern information society has reached such a stage when linearly predicting models and directions of consumer behavior are not possible. A comprehensive understanding of the incentives that shape consumer behavior is necessary. And these are manifested not only by incentives aimed at the direct satisfaction of the need, but also by incentives emanating from other areas of psychological response that are not related to consumer behavior. So, consumer behavior can be influenced by curiosity, cognitive activity, low consumption needs of the subject of consumption, etc. Sometimes the consumer activity can be initially provoked in relation to a particular product or service seemingly by negative effects, for example, public denudation of the buyer for the opportunity to buy goods at a discount.

This marketing strategy attracts both active participants and observers. From the point of view of linear average statistical logic, this action carries a negative assessment of consumer needs, but the facts show that this marketing strategy stimulates consumer behavior. Therefore the issues connected with the legal proceedings on the formation of negative business reputation cannot be considered within the framework of only traditional linguistic expertise. A comprehensive solution of this matter is necessary from the perspective of both linguists and psychologists, and economists (marketers).

Thus, reputation as a unity of meanings and representations in the consciousness of a market entity is a key tool that regulates the behavior of market participants at the decision-making stage. In essence, reputation is an indicator that determines the summation of the totality of business actions (comparison, analysis, modeling, forecasting, etc.). This demonstrates its importance of reputation and the aspiration of the market entity to carry out business activities (a system of business actions) aimed at improving the assessment system of the market entity (reputation) in the minds of other market participants.

The analysis of the definition allows us to conclude that the notion "business reputation" is basically considered as a moral and legal category. The objective absence of clear interpretations of this notion in the legal field leads to the problems of objectivity in the expert evaluation of case materials connected with this notion.

In Article 150, the Civil Code of the Russian Federation referred the notion of business reputation to "non-material values" on a par with life, health, personal dignity, personal inviolability, honor and good name, inviolability of private life, inviolability of home, personal and family secrets, freedom of movement, freedom to choose the place of residence and dwelling, the name of a citizen, authorship, other non-material values belonging to a citizen from birth or by force of law.

It should be noted that the law does not distinguish between the notions "business reputation of a citizen" and "business reputation of a legal entity", while Article 152, Paragraph 11 of the Civil Code of the Russian Federation directly states that the rules of the present article on protecting the business reputation of a citizen, with the exception of provisions on compensation for non-pecuniary damage, are accordingly applied to the protection of the legal entity's business reputation.

Even in Justinian's Digest there was a note stating that justice is an unchanging and constant will to grant everyone his right. The requirements of the law are as follows: to live honestly, not to harm others, to recompense everyone what belongs to him [11]. 
The Constitution of the Russian Federation in Article 17 recognizes and guarantees the rights and freedoms of a person and a citizen in accordance with the universally recognized principles and norms of the international law, while the exercise of human and citizen rights and freedoms should not violate the rights and freedoms of others.

The Resolution of the Plenum of the Russian Federation's Supreme Court from February 24, 2005 No. 3 noted that when resolving disputes on the protection of honor, dignity and business reputation, courts should ensure a balance between the right of citizens to protect honor, dignity, and business reputation, on the one hand, and other rights and freedoms guaranteed by the Constitution of the Russian Federation freedom of thought, speech, mass information; the right to freely seek, receive, transmit, produce and spread information in any legal way; the right to privacy, personal and family secrets; the right to appeal to state bodies and local government authorities, on the other hand.

Thus, in case of disputes about the protection of business reputation, courts should be guided not only by the norms of the Russian legislation, but also by the Convention for the Protection of Human Rights and Fundamental Freedoms [12], taking into account the legal position of the European Court of Human Rights, bearing in mind that the notion of defamation used by the European Court of Human Rights in its decrees is identical with the notion of dissemination of defamatory information that does not correspond to reality, contained in Article 152 of the Civil Code of the Russian Federation [13].

It should be noted that the circumstances that are relevant for filing a claim are:

1. the fact of dissemination of information;

2. the defamatory nature of this information;

3. their discrepancy with reality.

In this case, it is necessary to pay attention to the presence / absence of losses that have arisen as a result of dissemination of information discrediting business reputation.

In accordance with Paragraphs 42, 43 of the Order of the Russian Federation's Ministry of Finance from December 27, 2007 No. 153n [14], for accounting purposes, the value of the acquired goodwill is determined by calculation as the difference between the purchase price paid to the seller for the acquisition of the enterprise as a property complex (in whole or in part) and the amount of all assets and liabilities on the balance sheet as of the date of its purchase (acquisition).

Positive business reputation should be considered as a premium to the price paid by the buyer pending for the future economic benefits in connection with acquired unidentifiable assets, and accounted for as a separate inventory object.

Negative business reputation should be considered as a discount from the price presented to the buyer due to the absence of factors for the presence of stable buyers, reputation for quality, marketing and sales skills, business connections, management experience, staff qualifications, etc.
In this regard, it seems necessary to consider the possibility of conducting financial and economic expertise to resolve all issues that are relevant for filing a claim for protecting business reputation.

The analysis of the definition of "business reputation" has allowed identifying the lack of difference in the pragmatics of this notion. Thus, the key and semantic notions "business" and "reputation" are unchangeable, and their semantics are determined not by the object (citizen, legal entity), but by the noun "reputation" and the adjective "business (like)" (which indicates affiliation of reputation).

And in this respect, there is no difference between a citizen and a legal entity in the basic senses, since both the subjects are in the semantic field of the notion "reputation". But the Law restricts the affiliation of reputation not to all, but to a "business" field; as a consequence, a citizen and a legal entity have common properties and differ in a particular way. It should also be noted that, psychologically, a legal entity and a citizen are not perceived identically: a citizen is treated as a subject, a legal entity - as a group entity. At the same time, it is determined in social psychology that the subject and the group subject have the same properties [15].

Besides, in the "Handbook of Civil Judges" business reputation is defined as a moral and moral-legal category consisting of a set of professional qualities of an individual or legal entity [16]. It remains unclear what are the principles of the structure of professional qualities, what qualities are more significant, which of them are less significant in the implementation of professional actions. These issues also relate to such a section of psychology as acmeology. It is impossible to carry out this research within the framework of linguistic judicial expertise as the matter of professionally significant qualities goes beyond the competence of the expert linguist.

At the same time, the set of professional qualities of an individual and legal entity have a single methodological field, but in practice they will be different in their particular expression. It should be noted that this practical difference at the private level will be the main problem in constructing the methodological basis of judicial psychological expertise.

Withal, if the notion "business reputation" is defined only through the notion "a set of professional qualities", then we will come to a methodological collapse, when these qualities will be specific and characteristic of a certain area of activity. It is observed particularly in the practice of performing linguistic expertise, where, as a result, the notion "business reputation" is not regarded as an independent definition, and not the definition of this notion characteristic of a given firm is defined, but only its general social linguistic component is considered. There happens ignorance of professionally significant qualities, their unification in the general approach to the definition of activity. So, for example, the expert conclusion states that if the text contains information about activities, then there is information about both business competence and business reputation [17].

The notion of activity is too broad to draw direct parallels. The activity itself is only the bearer of reputation (the 
reputation itself, as a consequence of the external evaluation of products and results, lies beyond the activity in the public and individual consciousness in the form of an appraisal opinion), and competence should be distinguished from the content of the activity with the help of its (activity) sociopsychological (acmeological) analysis. Or the question in the court's decision: "Is this phrase insulting to the head of the city of Ivanovo, Troeglazov V.V.?", and the expert's answer to it based only on the linguistic analysis of the text [18]. In this case, it is an important matter to analyze the perception of insult by Troeglazov's personality in psychological terms, and if this is the head of the city, then it is important to analyze the component from the socio-psychological point of view. The question is formulated precisely in that manner when the fact of defamation can be determined only by a complex psychological-linguistic or psycho-linguistic expertise.

In the "Judicial Review Handbook: Judicial Expertise: Theory and Practice, Typical Issues and Non-Standard Situations", standard questions are given in connection with civil cases on business reputation protection:

"1. Does the text contain negative information about ... (surname, name, patronymic; the name of the legal entity), his activity and his personal business and moral qualities? What specific statements contain this information and what is their semantic orientation?

2. If the above-mentioned phrases contain negative information about ... (surname, name, patronymic; the name of the legal entity), then in what form are they expressed: statements, assumptions, questions?

3. Does the lingua-stylistic analysis of the text confirm that it contains phrases in the form of statements with information about the violation of the current legislation, generally accepted moral norms and principles by Mr. (surname, name, patronymic)?

4. In what meaning is the word (word combination, phrase, construction) used in the text of the publication?

5. What is the compositional structure of the text of articles (article), what stylistic devices are used by the author, and how do they describe the characters of the publication?

6. Are the data, stated in the text, statements about facts, if so, what kind of, or value judgments, the opinion of the author of the publication?" [19].

Concerning the first question, there arise serious doubts about the readiness of the linguistic methodological apparatus to correlate the content of an individual or legal entity's activity (there is simply no such content for the linguist expert and the analysis of his activities goes beyond his competence). But if there is no content of activity, then how the correlation of negatively directed expressions on business qualities is objectively constructed. It turns out that in order to answer this question, the linguist must initially build the object of an information attack, its content, and its psychology, and only in this case it is possible to speak objectively about the direction of the text under consideration. The rest of the questions are of an applied nature, which are valid when considering the object of impact as a whole.
It is also important that the authors recommend these issues not only when considering cases about business reputation, but also about the protection of honor and dignity, which confirms the idea of one-sidedness of linguistic judicial expertise in this type of cases once again.

Let us denote a number of benchmarks whose solution will make it possible to circumvent the emerging methodological problems:

1. If one is based on the mission of the enterprise where the content of business reputation is determined, then the expert will be focused on the subject assumptions about the reputational benchmarks set by the injured party, and in this case there is no need to strive for some universal matrix of a set of qualities of business reputation. If an enterprise does not have a mission in any form of its expression, then its concern for business reputation in the market is doubtful. However, in this case there arises a question as to the business reputation of an individual whose mission is not spelled out in his documents.

In this case, a complex question to a psychologist and a linguist or a psycholinguist may sound in this form: "Does the meaning of the text correlate with the content of a legal entity's business reputation placed in the mission?"

2. The second important point is the definition of actions from the viewpoint of the victim whose actions have a targeted focus on the formation of the business reputation of himself as a subject of market relations, and, in this case, it is not important whether this is an individual (for example, a hired manager) or a legal entity.

Formation of a positive image in the mind of a consumer can be part of the strategy of the subject's image in the market, and this policy is invested (advertising, PR actions, etc.). In this case, a certain stable image of a market entity is formed in the mind of a consumer, and the expert is faced with the question of how widespread negative information influences the whole value-semantic field that has arisen.

In this case, the object is a certain integrated image reflected in the whole range of documents, from published image articles to financial and economic documents, which, from the plaintiff's point of view, reflect the amount of funds invested in the image and the amount of lost capital as a result of the spread negative information.

In case of an individual's business reputation, the content of the image can be reflected in the reference from the place of work (reviews, ratings, results of sociological research, etc.). And in this case it is more expedient to appoint complex psycholinguistic and financial-economic expertise.

In this case, the question about a complex psychologicallingua-economic expertise may sound as follows: "What is the target orientation of the text? Does the target orientation of the text negatively affect the formed image of the business entity? Are reputational losses expressed in the financial and economic indicators of the business entity?"

Consumer behavior not always and practically never follows the path of one chain - stimulus-response. Consumer behavior is a generalizing notion; a notion that includes factors 
and conditions on the basis of which a consumer determines the urgency of the need, makes a decision, chooses the goods, consumes the goods and determines the degree of satisfaction.

In the effectuation of image policy, the subject of market relations, consciously or unconsciously, is guided precisely by the methodological models of consumer behavior. The valueand-sense model developed by him must meet all the components of the system of consumer behavior. When conducting expert examination, it is important to understand whether the damage of this model is systematic, whether it will affect the consumer behavior of market participants. It is in such a comprehensive understanding of the subject matter of the litigation -"business reputation" - we can talk about defaming the reputation of a business entity.

Thus, the results of complex psycho-linguistic and economic expertise expand the scope of understanding and assessing the impact of speech information and allow the court to assess the nature of the statement more fully when considering cases of business reputation protection [20].

While conducting complex psychological-lingua-economic expertise in the consideration of cases on business reputation protection, an important aspect is to define the qualifications of judicial experts. The questions of judicial experts' qualifications have repeatedly been the subject of discussion among such scientists as E.R. Rossinskaya, E.I. Galyashina, A.A. Leontiev, V.I. Mamay, V.A. Prorvich, and M.V. Zhizhina. All the scientists unanimously concluded that an important factor in choosing an expert is his qualification, while the problem of determining qualification remains open. It should be noted that the legal bases, the principles of organization and the main directions of state judicial-expert activity in the Russian Federation are defined by Federal Law No. 73-FZ "On state judicial-expert activity in the Russian Federation" dated May 31, 2001. Federal Law in Article 4 establishes that state judicial-expert activity is based on the principles of legality, observance of the rights and freedoms of a person and a citizen, the rights of a legal entity, as well as the independence of an expert, objectivity, comprehensiveness and completeness of the researches conducted using the modern achievements of science and technology. The implementation of the principles of state judicial-expert activity is ensured by a system of criteria for the selection of employees in recruitment and their attestation by state judicial-expert institutions that carry out judicial expertise.

According to Article 13 of the present Federal Law, the determination of the level of experts' professional training and their certification for the right to conduct judicial expertise independently is carried out by expert-qualification commissions in the manner established by the regulatory legal acts of the corresponding federal executive bodies. The level of professional training of experts is subject to reconsider by these commissions every three years.

It should be noted that according to Article 41 of the present Federal Law, the principles of state judicial-expert activity apply to non-state experts, while the practical mechanism for ensuring the level of qualification of non-state experts does not exist in all organizations. This is facilitated by a gap in the legislation. We should agree with the opinion of N. Alekhin who believes that the law attaches uniform requirements to an expert opinion, but there are no specific legislative requirements regarding the qualification of the expert body of non-state expert institutions.

The studies indicate that this issue should be solved by a competent body (for example, the expert chamber) which will develop an accreditation system for experts. At the same time, certification of the competence of employees belonging to state judicial-expert organizations is carried out on a compulsory basis, but for other persons - voluntarily.

Powers for competence certification are vested in the federal executive body determined by the government. However the issue of motivating non-state experts remains open while passing the procedure of competence certification, since a person who does not have the corresponding certificate may be brought in for expert examination.

\section{References}

[1] <Historical Dictionary of Gallicisms of the Russian Language> http://gallicismes.academic.ru/33463/\%D1\%80\%D0\%B5\%D0\%BF\%D1 $\% 83 \% \mathrm{D} 1 \% 82 \% \mathrm{D} 0 \% \mathrm{~B} 0 \% \mathrm{D} 1 \% 86 \% \mathrm{D} 0 \% \mathrm{~B} 8 \% \mathrm{D} 1 \% 8 \mathrm{~F}$ (10.11.2013).

[2] <Dictionary of Business terms> http://dic.academic.ru/dic.nsf/business/11503 (10.11.2013).

[3] <Dictionary of Foreign Words of the Russian Language > http://dic.academic.ru/dic.nsf/dic_fwords/31428/\%D0\%A0\%D0\%95\%D $0 \% 9 \mathrm{~F} \% \mathrm{D} 0 \% \mathrm{~A} 3 \% \mathrm{D} 0 \% \mathrm{~A} 2 \% \mathrm{D} 0 \% 90 \% \mathrm{D} 0 \% \mathrm{~A} 6 \% \mathrm{D} 0 \% 98 \% \mathrm{D} 0 \% \mathrm{AF}$ (10.11.2013).

[4] B.A. Reisberg, L.Sh. Lozovsky, E.B. Starodubtseva, Contemporary Dictionary of Economics, 2nd ed., corrected, M.: INFRA, 1999, 479 p.

[5] < Dictionary of Economics http://dic.academic.ru/dic.nsf/econ_dict/12830 (10.11.2013)

[6] About Banks and Banking Activities. The Law of the USSR from December 11, 1990. № 1829-I, Gazette of the Congress of People's Deputies of the USSR and the Supreme Soviet of the USSR, No. 52, Art. 1155, 1990.

[7] About the Central Bank of the Russian Federation (Bank of Russia). The Federal Law from December 2, 1990, Gazette of the Congress of People's Deputies of the RSFSR, No. 27, Art. 356, 1990.

[8] About Banks and Banking Activities. The Federal Law from December 2, 1990. № 395-I, Gazette of the Congress of People's Deputies of the RSFSR, No. 27, Art. 357, 1990.

[9] About Competition and Restriction of Monopolistic Activity in Commodity Markets. The Law of the RSFSR from March 22, 1991. № 948-I, Gazette of the Congress of People's Deputies of the RSFSR and the Supreme Council, No. 16, Art. 499, 1991.

[10] About Trademarks, Service Marks and Appellations of Origin of Goods. The Law of the RF from September 23, 1992. № 3520-1, Gazette of the Congress of People's Deputies of the Russian Federation and the Supreme Council of the Russian Federation, No. 42, Art. 2322, 1992.

[11] L.L. Kofanov, Justinian's Digest. Vol.1. Books I-IV, M, 2002, 589 p.

[12] Convention for the Protection of Human Rights and Fundamental Freedoms ETS N 005 (Rome, November 4, 1950) (with corrections and additions from September 21, 1970, December 20, 1971, January 1, 1990, November 6, 1990, May 11, 1994). Collection of Legislation of the Russian Federation, No. 20, Art. 2143, 1998.

[13] About the judicial practice in cases of protection of honor and dignity of citizens, as well as business reputation of citizens and legal entities. Resolution of the Plenum of the Supreme Court of the Russian Federation from February 24, 2005. № 3, Bulletin of the Supreme Court of the Russian Federation, № 4, 2005.

[14] About Approval of the Accounting Regulations. Accounting for Intangible Assets. The Order of the Russian Federation's Ministry of 
Finance from December 27, 2007 No. 153n (PBU 14/2007), Russian Newspaper, No. 22, 2008.

[15] G.M. Andreeva, Social Psychology. M.: Aspect Press, 2003, 229 p.

[16] N.K. Tolcheeva, Handbook of Civil Judges, 2nd ed., corrected and added., M.: Prospekt, 2008, 656 p.

[17] < Guild of Expert Linguists http://www.rusexpert.ru/books/cena_slova3/004.htm\#6 (10.11.2013)
[18] <Guild
of
Expert
Linguists http://www.rusexpert.ru/books/cena_slova3/005.htm (10.11.2013)

[19] E.R. Rossinskaya, E.I. Galyashina, Judicial Review Handbook: Judicial Expertise: Theory and Practice, Typical Issues and Non-Standard Situations, M.: Prospekt, 2012, 464 p.

[20] A.V. Pominov, O.V. Dubrovin, "Protection of Honor, Dignity and Business Reputation", Yuzhnouralsky Legal Bulletin, No. 4, 2013. 